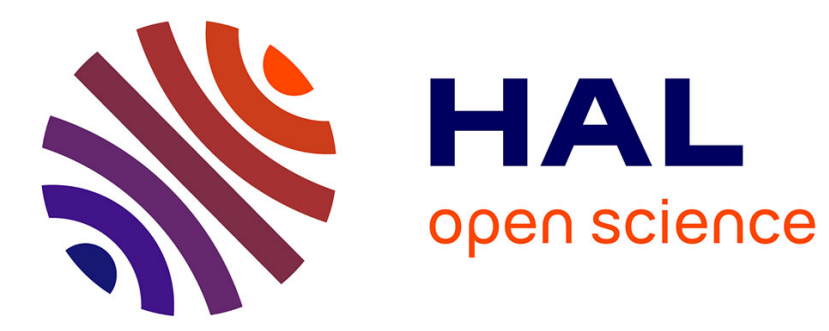

\title{
Cyclic behaviour constitutive modelling of a tempered martensitic steel including ageing effect
}

\author{
Zhanping Zhang, Gérard Bernhart, Denis Delagnes
}

\section{To cite this version:}

Zhanping Zhang, Gérard Bernhart, Denis Delagnes. Cyclic behaviour constitutive modelling of a tempered martensitic steel including ageing effect. International Journal of Fatigue, 2008, 30 (4), pp.706-716. 10.1016/j.ijfatigue.2007.05.003 . hal-01715080

\author{
HAL Id: hal-01715080 \\ https://hal.science/hal-01715080
}

Submitted on 11 Jan 2019

HAL is a multi-disciplinary open access archive for the deposit and dissemination of scientific research documents, whether they are published or not. The documents may come from teaching and research institutions in France or abroad, or from public or private research centers.
L'archive ouverte pluridisciplinaire HAL, est destinée au dépôt et à la diffusion de documents scientifiques de niveau recherche, publiés ou non, émanant des établissements d'enseignement et de recherche français ou étrangers, des laboratoires publics ou privés. 


\title{
Cyclic behaviour constitutive modelling of a tempered martensitic steel including ageing effect
}

\author{
Zhanping Zhang ${ }^{\mathrm{a}, *}$, Gérard Bernhart ${ }^{\mathrm{b}}$, Denis Delagnes ${ }^{\mathrm{b}}$ \\ ${ }^{a}$ Electromechanics and Materials Engineering College, Dalian Maritime University, Dalian 116026, China \\ ${ }^{\mathrm{b}}$ Research Centre on Tools, Materials and Processes (CROMeP), Ecole des Mines d'Albi-Carmaux, 81013 Albi CT cedex 09, France
}

\begin{abstract}
Cyclic behaviour of a tempered martensitic tool steel is studied in relation with the tempering state and a cyclic fatigue-ageing constitutive model is proposed. Kinetics of tempering and hardness evolution in the form of Johnson-Mehl-Avrami relation is introduced in an anisothermal constitutive model developed in the framework of the thermodynamics of irreversible processes. Model parameter identification methodology based on two optimised cyclic tests is explained and applied in the temperature range from room temperature up to $600{ }^{\circ} \mathrm{C}$ on a $55 \mathrm{NiCrMoV} 7$ tool steel with four different initial hardness levels. Validation is performed comparing model prediction with experimental results obtained on one hand during cyclic tests performed above the tempering temperature inducing an important micro-structural evolution as well as for samples with different tempering conditions not used for the identification process.
\end{abstract}

Keywords: Fatigue behaviour; Ageing; Tempering ratio; Tool steel; Cyclic constitutive model; Micro-structure evolution

\section{Introduction}

Development of numerical simulation methods, such as finite element method (FEM) and boundary element method (BEM), becomes one of the most important, powerful and time saving tool in design and innovation of industrial products. However, accurate simulation and numerical prediction need proper mathematical, mechanical and physical models. Cyclic constitutive models have been developed for decades for metallic materials subjected to high-temperature fatigue, and a large number of cyclic plasticity models with different complexities can be found in the literature. Particularly, phenomenological models, for which each physical phenomenon is described with a corresponding macroscopic internal variable, are widely

\footnotetext{
${ }^{*}$ Corresponding author. Tel.: +86 411 84725568; fax: +86 411 84723556

E-mail address: zzp@newmail.dlmu.edu.cn (Z. Zhang).
}

used due to their ability to reproduce many experimental features. For example Miller [1] and Chaboche models [2] are well known and frequently used in aeronautical and nuclear industries. This last framework was also chosen in previous works as the basis for describing and modelling the anisothermal behaviour of martensitic tool steels [3-6].

Nevertheless previous investigations were conducted with the assumption that material has a stable micro-structure. This is for example the case when testing temperature is lower than tempering temperature. However, as properties are changing with tempering temperature, material parameter identification has to be performed for each final tempering state. Moreover, numerous investigations have shown that the die-workpiece interface may reach temperature levels higher than the tempering ones [7,8]. In such conditions, steel may be subjected during its life to a continuous evolution of its micro-structure and related properties. As a consequence, the derivation of a model able to take into account these micro-structural evolutions would be of prime interest for industrial applications where material initial and final state can vary from one die to another, 
and where working conditions are different from one location to another.

In recent literature some models involving micro-structure evolutions are reported. These models can be divided into three major categories:

- Mixture law models, where total strain and temperature are common variables in all material phases and where classical phenomenological models are applied to each phase. Micro-structure influence on cyclic behaviour is taken into account through a mixture law based on the volume fraction of phases. This type of model was basically applied to $\mathrm{Fe}-\mathrm{C}$ alloys in order to evaluate the residual stresses and distortions after quenching or heat-treatment [9-14]. They can be used for all twophase or even multiphase materials, but it requires the knowledge of the properties and behaviours of every phase; however, it is often difficult to measure the properties of individual phases and to get the related constitutive equations.

- Macroscopic models in which an internal variable is correlated to the micro-structure of material. For example, Cailletaud [15] proposed an internal variable representing the quantity of precipitated phase in an IN100 alloy. The same author [16,17] introduced also the ageing of AS7U3G Al-alloy in an anisothermal elasto-visco-plasticity model using the material hardness as representative of the transformed proportion of alloy. The drawback of such model formulation is to be sometimes far away from the physical phenomena that occur in the material, on the other hand the advantage is to be easily identified, using in general mechanical property measurements. The model proposed in this paper belongs to such kind of models.

- Models referring explicitly to a measured micro-structural parameter. For example Marquis et al. [18] treated the ageing effect of $\mathrm{Al}-\mathrm{Cu}$ alloy (AU4G) using the volume fraction of precipitation. His model was verified valid also for $\mathrm{Al} / \mathrm{SiC}$ composite by Chaboche et al. [19]. Secondary dendrite arm spacing (SDAS) was proposed by Smith et al. [20] as a parameter in an elastovisco-plastic model for Al-alloy for automotive industry. Devy [21] introduced the size of precipitated $\gamma^{\prime}$ particles into a cyclic constitutive model for an Astroloy alloy. The parameter identification of this type model is based on the investigation of the micro-structure of the materials that can be very time-consuming.

In this work an anisothermal model is investigated to describe the fatigue behaviour of a martensitic tool steel subjected to evolution of his micro-structure during tempering and mechanical cycling at high temperature. In order to achieve this goal, a macroscopic parameter called "tempering ratio" and based on Vickers hardness measurement is introduced. Model formulation, identification methodology and validation of the model are successively presented.

\section{Tempering ratio and experimental fatigue test}

\subsection{Material and heat-treatment}

$55 \mathrm{NiCrMoV} 7$ hot-work tool steel, widely used in forging industry, with a chemical composition ( $\mathrm{wt}^{\mathrm{O}} \%$ ) of $0.56 \mathrm{C}, 1.7 \mathrm{Ni}, 1.0 \mathrm{Cr}, 0.5 \mathrm{Mo}, 0.1 \mathrm{~V}, 0.2 \mathrm{Si}$ and $0.7 \mathrm{Mn}$ was selected for this investigation. The steel was austenitised at $850^{\circ} \mathrm{C}$ for $1 \mathrm{~h}$ followed by a single tempering for $2 \mathrm{~h}$ at $350{ }^{\circ} \mathrm{C}, 460{ }^{\circ} \mathrm{C}, 560^{\circ} \mathrm{C}$ and $600^{\circ} \mathrm{C}$, resulting in a tempered martensitic structure with a measured hardness level, respectively, equal to $580 \mathrm{HV}_{0.2}, 509 \mathrm{HV}_{0.2}, 457 \mathrm{HV}_{0.2}$ and $376 \mathrm{HV}_{0.2}$ (Table 1). These tempering conditions correspond to the usual steel states required for industrial applications.

\subsection{Micro-structural parameter: tempering ratio parameter}

The tempering process can be considered as a phase transformation promoted by diffusion from an unstable state (martensite) towards a stable equilibrium state (ferrite + globular carbides), which corresponds to the annealed state of steel. The tempered steel is therefore in a quasi equilibrium state (ferrite + primary carbides and small secondary carbides) which is supposed to evolve towards a stable equilibrium state as long as thermal and mechanical conditions promote this evolution.

In order to define the micro-structural state, a definition of a tempering ratio $\left(\tau_{\mathrm{v}}\right)$, based on the measurement of hardness of the steel, was introduced in previous works [22-24]: $\tau_{\mathrm{v}}=\left(\mathrm{HV}-H_{0}\right) /\left(H_{\infty}-H_{0}\right)$ where $H_{0}$ is the hardness after quenching, $H_{\infty}$ is the hardness in the annealed state, and $\mathrm{HV}$ is the hardness obtained after a given tempering treatment. According to this definition, tempering ratio values fall between 0 (as-quenched state) and 1 (annealed state). From this definition, a tempering kinetic law was proposed in the form of the Johnson-MehlAvrami type equation: $\tau_{\mathrm{v}}=1-\exp \left(-(D \cdot t)^{m}\right)$, where $t$ is the tempering time, $m$ is the ageing exponent depending on the material and the previous austenitising-quenching heat-treatment. $D$ depends on tempering temperature and follows the Arrhenius equation $D=D_{0} \exp (-Q / R T)$, where $D_{0}$ is the pre-exponential constant, $Q$ is the activation energy of the tempering transformation, $R$ is the perfect gas constant (equal to $8.31 \mathrm{~J} \mathrm{~K}^{-1} \mathrm{~mol}^{-1}$ ) and $T$ is the

Table 1

Heat-treatment, corresponding hardness and tempering ratio $\left(\tau_{\mathrm{v}}\right)$

Quenching condition: austenitisation at $850^{\circ} \mathrm{C}$ for $1 \mathrm{~h}$, vacuum quenching Tempering condition: $2 \mathrm{~h}$ at the selected temperature

\begin{tabular}{lll}
\hline $\begin{array}{l}\text { Tempering temperature } \\
\left({ }^{\circ} \mathrm{C}\right)\end{array}$ & $\begin{array}{l}\text { Vickers hardness } \\
\left(\mathrm{HV}_{0.2}\right)\end{array}$ & $\begin{array}{l}\text { Tempering ratio } \\
\left(\tau_{\mathrm{v}}\right)\end{array}$ \\
\hline 350 & 580 & 0.3640 \\
460 & 509 & 0.4788 \\
560 & 457 & 0.5636 \\
600 & 376 & 0.7102 \\
\hline
\end{tabular}


tempering temperature in Kelvin. Identification of the model parameters [22] gave following values $H_{0}=$ $776 \mathrm{HV}_{0.2}, \quad H_{\infty}=210 \mathrm{HV}_{0.2}, \quad D_{0}=2.7 \times 10^{8} \mathrm{~s}^{-1}, \quad Q=$ $231 \mathrm{~kJ} \mathrm{~mol}^{-1}, m=0.0518$.

Based on this definition, the tempering ratio values corresponding to the four tempering conditions used for fatigue sample manufacturing are listed in Table 1.

\subsection{Fatigue tests program}

Isothermal fatigue behaviour of the steel at each tempering state was investigated in the $20-600{ }^{\circ} \mathrm{C}$ range. All fatigue tests were carried out with a MTS 810 closed-loop servo-hydraulic testing machine and Teststar II $^{\mathrm{TM}}$ controller connected to a personal computer. Samples were subjected to total strain fatigue controlled test at the following temperatures: $20{ }^{\circ} \mathrm{C}, \quad 300{ }^{\circ} \mathrm{C}, \quad 400{ }^{\circ} \mathrm{C}, \quad 500^{\circ} \mathrm{C}$ and $600{ }^{\circ} \mathrm{C}$. The round specimens were mounted in water-cooled grips and heating was achieved with a $6 \mathrm{~kW}$ induction generator. Temperature was controlled on the middle of the sample by mechanically applied thermocouples [5]. Strain is recorded with a $12 \mathrm{~mm}$ gauge length contact extensometer with alumina rods. Cyclic tests were started after heating at a rate of $200{ }^{\circ} \mathrm{C} / \mathrm{min}$ and a temperature stabilisation of $75 \mathrm{~s}[23,25]$.

Two types of fatigue tests were performed in reversed total strain amplitude conditions with a triangular waveform $[4,23]$ :

- Test type one. Total strain amplitude is fixed to $\Delta \varepsilon_{\mathrm{t}}= \pm 0.8 \%$ during all the tests, whereas strain rate is kept constant at $10^{-2} \mathrm{~s}^{-1}$ during a first phase. The number of cycles was selected in order to reach a near constant cumulated plastic strain " $p$ " close to $4 \mathrm{~mm} / \mathrm{mm}$ whatever the testing temperature and hardness, in order to ensure that the material has reached the quasi-linear cyclic softening stage. In order to study strain rate sensitivity of the steel, three levels of strain rates were selected to cover the industrial strain rate conditions arising when forging dies are used in mechanical or hydraulic presses. Strain rate is then varied from $10^{-2} \mathrm{~s}^{-1}$ to $10^{-3} \mathrm{~s}^{-1}$ and $10^{-4} \mathrm{~s}^{-1}$ and only three cycles were performed at each strain rate. This test is used for kinematic and isotropic hardening parameter identification, as well as for Young's modulus and viscous parameter identification.

- Test type two. Total strain amplitude $\Delta \varepsilon_{\mathrm{t}}$ was changed in the following sequence: $\pm 0.6 \%, \pm 0.7 \%, \pm 0.8 \%, \pm 0.9 \%$, and $\pm 0.7 \%$, whereas strain rate was kept constant at $10^{-2} \mathrm{~s}^{-1}$. The number of cycles performed at each strain amplitude was selected to reach a cumulated plastic strain " $p$ " close to $1 \mathrm{~mm} / \mathrm{mm}$. This test allows a verification of the parameter identified with test type one and is used for strain memory parameter validation.

At each temperature, only two fatigue specimens are needed to determine all the parameters of the cyclic constitutive model when performing the previous optimised test procedures. Depending on testing and tempering temperatures, the material micro-structure is expected to be "stable" or "unstable" during the whole testing procedure starting at the beginning of the heating up, as shown in Table 2.

\subsection{Results}

The typical cyclic behaviour of the $55 \mathrm{NiCrMoV} 7$ steel is shown in Fig. 1 where the half-stress amplitude is plotted according to cumulated plastic strain at four different testing temperatures and for each hardness level. Tempered $55 \mathrm{NiCrMoV} 7$ steel undergoes cyclic softening regardless of the initial hardness and testing temperature, i.e. halfstress amplitude decreases with cumulated plastic strain (i.e. the number of cycles). This softening could be divided into two-phases, which are the rapid softening phase during the initial few hundred cycles (cumulated plastic strain $<1 \mathrm{~mm} / \mathrm{mm}$ ) followed by a slow quasi-linear softening phase till rupture [26,27]. The former is generally explained by the rapid change of dislocation density inherited from the quench treatment, the later is related to the formation of dislocation sub-structure and carbide coarsening under the action of time and temperature as well as cyclic load $[8,25,27]$.

As previously shown [25], cyclic softening behaviour is strongly influenced by testing temperature and tempering ratio of the steel (values reported are calculated at the end of the fatigue test procedure). Generally, the higher the tempered hardness of steel is, the higher is the yield strength and the cyclic stress amplitude (see Fig. 1a $\left.\left(20^{\circ} \mathrm{C}\right), \mathrm{b}\left(300^{\circ} \mathrm{C}\right)\right)$. However, for fatigue tests at elevated temperature $>400{ }^{\circ} \mathrm{C}$, increase of the experimental stress amplitude is not proportional to the hardness (see Fig. 1c $\left.\left(500{ }^{\circ} \mathrm{C}\right), \mathrm{d}\left(600^{\circ} \mathrm{C}\right)\right)$. As discussed in detail in previous work [25], where a detailed analysis of the effect of ageing on the cyclic behaviour of this steel can be found, it is due to the effect of ageing during fatigue procedure (heating up, temperature stabilisation followed by the fatigue cycling) when testing temperature is higher or equal to the tempering temperature. Under these conditions, the initial hardness no more controls the fatigue behaviour. Conversely, the tempering ratio value is the relevant parameter taking into account the micro-structure evolution during the whole fatigue procedure. As a matter of fact, all samples with a close value of tempering ratio have a similar cyclic softening behaviour.

Table 2

Fatigue test program (for test type one and two) and micro-structure stability under these test conditions

\begin{tabular}{llllll}
\hline Tempering & \multicolumn{5}{l}{ Testing temperature $\left({ }^{\circ} \mathrm{C}\right)$} \\
\cline { 2 - 6 } temperature $\left({ }^{\circ} \mathrm{C}\right)$ & 20 & 300 & 400 & 500 & 600 \\
\hline 600 & Stable & Stable & Stable & Stable & Unstable \\
560 & Stable & Stable & Stable & Stable & Unstable \\
460 & Stable & Stable & Stable & Unstable & Unstable \\
350 & Stable & Stable & Unstable & Unstable & Unstable \\
\hline
\end{tabular}



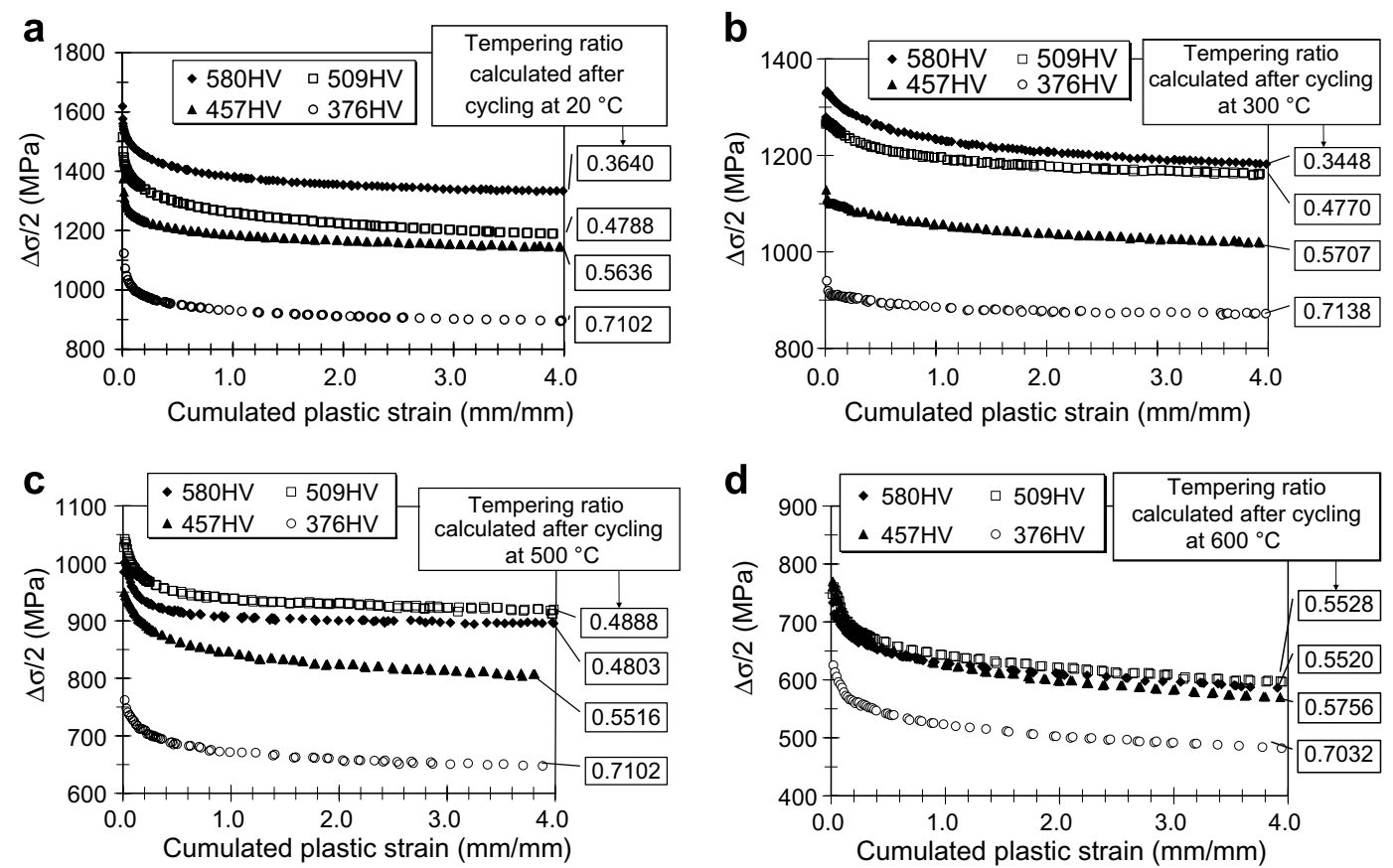

Fig. 1. Half-stress amplitude evolution according to cumulated plastic strain, for the four investigated initial hardness $\left(\Delta \varepsilon_{\mathrm{t}}= \pm 0.8 \%\right)$ : (a) $20{ }^{\circ} \mathrm{C},(\mathrm{b})$ $300{ }^{\circ} \mathrm{C}$, (c) $500^{\circ} \mathrm{C}$, (d) $600{ }^{\circ} \mathrm{C}$.

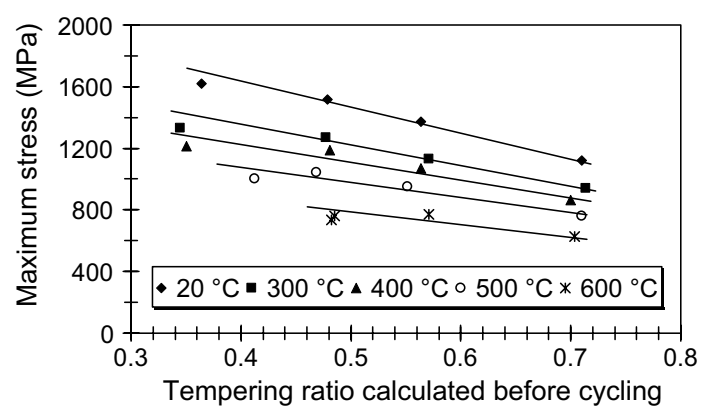

Fig. 2. Maximum stress measured during the first cycle $\left(\varepsilon_{\mathrm{t}}=+0.8 \%\right)$ according to the calculated tempering ratio before cycling.

As regard to a constitutive modelling, there is a direct impact of the micro-structure evolution during the ageing on kinematic hardening (back stress) as well as on the isotropic hardening (drag stress). This can be seen in Fig. 2 where the maximum stress during the first strain increase of the first fatigue cycle (directly related to the kinematic part of a constitutive model) is plotted against the tempering ageing parameter calculated at the beginning of the cycling (i.e. after heating up and temperature stabilisation). A linear relationship depending on testing temperature is obviously observed. A similar relationship is found (see Fig. 3) when plotting the half-stress amplitude (correlated to the isotropic hardening) at a cumulated plastic strain of $p=4 \mathrm{~mm} / \mathrm{mm}$ according to the tempering ratio calculated after cycling.

Consequently, interaction between fatigue and ageing should be reproduced in a constitutive model for a proper and general use for fatigue design purposes of such steels.

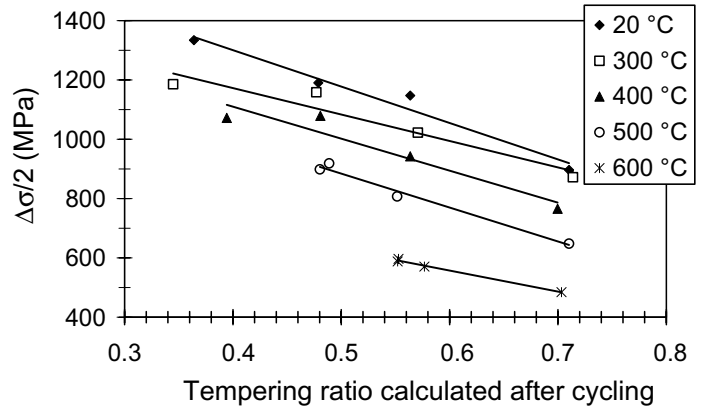

Fig. 3. Half-stress amplitude at cumulated plastic strain $p=4 \mathrm{~mm} / \mathrm{mm}$ with respect to the calculated tempering ratio after cycling.

\section{Cyclic constitutive model with ageing}

Anisothermal cyclic plasticity model reported in more details in Ref. [5] is used as the basis for introduction of ageing effect. In order to be able to reproduce the experimental features in cyclic conditions, it takes into account kinematic hardening, strain rate and strain memory effects, and uses two back stresses to describe the non-saturating cyclic softening of such tempered martensitic steels. State equations and evolution laws were derived from dissipation potential and thermodynamic potential (free energy) in the framework of the thermodynamics of irreversible processes.

\subsection{Introduction of ageing effect in cyclic constitutive model}

A new internal scalar variable $\tau_{\mathrm{v}}$ (tempering ratio) related to steel ageing is introduced into the previous 
elasto-visco-plastic model [5]; its associated thermodynamic variable is called " $Z$ ". Considering ageing-fatigue, free energy was derived in the following form ${ }^{1}$ :

$$
\begin{aligned}
\rho \psi\left(\underline{\varepsilon}_{\mathrm{e}}, \underline{\alpha_{i}}, r_{j}, \tau_{\mathrm{v}}, T\right)= & \frac{1}{2} \underline{\varepsilon}_{\mathrm{e}}: \underline{\underline{C}}: \underline{\varepsilon}_{\mathrm{e}}+\sum_{i=1}^{2} \frac{1}{3} c_{i} \cdot a_{i} \cdot \underline{\alpha_{i}}: \underline{\alpha_{i}} \\
& +\frac{1}{2} Q_{1} \cdot r_{1}^{2}+\frac{1}{2} b \cdot Q_{2}(q) \cdot r_{2}^{2} \\
& +\frac{L}{2} \cdot\left(1-\tau_{\mathrm{v}}\right)^{2}
\end{aligned}
$$

where $c_{i}, a_{i}, Q_{1}, Q_{2}, b, L$ are scalar model parameters depending on temperature and steel grade, $\underline{\alpha}_{i}, r_{1}, r_{2}, \tau_{\mathrm{v}}$ internal variables and $X_{i}, R_{1}, R_{2}, Z$ their associated variables, $q$ is the strain memory variable, $\underline{\varepsilon}_{\mathrm{e}}$ and $\underline{\varepsilon}_{\mathrm{p}}$ are elastic and plastic strain tensors.

From Eq. (1), the state equations can be derived:

$\underline{\sigma}=\rho \frac{\partial \psi}{\partial \underline{\varepsilon}_{\mathrm{e}}}=\underline{\underline{C}} \cdot \underline{\varepsilon}_{\mathrm{e}}$

$\underline{X_{i}}=\rho \frac{\partial \psi}{\partial \underline{\alpha_{i}}}=\frac{2}{3} c_{i} \cdot a_{i} \cdot \underline{\alpha_{i}}$

$R_{1}=\rho \frac{\partial \psi}{\partial r_{1}}=Q_{1} \cdot r_{1}$

$R_{2}=\rho \frac{\partial \psi}{\partial r_{2}}=b \cdot Q_{2}(q) \cdot r_{2}$

$Z=\rho \frac{\partial \psi}{\partial \tau_{\mathrm{v}}}=-L \cdot\left(1-\tau_{\mathrm{v}}\right)$

The micro-structure change, i.e. evolution of tempering ratio $\tau_{\mathrm{v}}$, is associated to an ageing potential $\Omega_{\mathrm{v}}$ [19]. Therefore, total dissipation potential can be divided into $\Omega_{\mathrm{v}}$ and plastic potential $\Omega_{\mathrm{p}}$ :

$\Omega=\Omega_{\mathrm{p}}\left(\underline{\sigma}, \underline{X_{i}}, R_{j} ; \underline{\alpha_{i}}, r_{j}, p, T\right)+\Omega_{\mathrm{v}}\left(Z ; \tau_{\mathrm{v}}, T\right)$

Visco-plastic dissipation potential is selected in the form $[6,28]$ :

$\Omega_{\mathrm{p}}=\frac{K}{n+1}\left\langle\frac{f}{K}\right\rangle^{n+1}$

where

$$
\begin{aligned}
f= & G+\sum_{i=1}^{2}\left(\frac{3}{4 a} \underline{X_{i}}: \underline{X_{i}}-\frac{1}{3} c^{2} \cdot a_{i} \cdot \underline{\alpha_{i}}: \underline{\alpha_{i}}\right)+\frac{1}{2 Q_{1}} R_{1}^{2} \\
& +\frac{1}{2 Q_{2} b_{2}^{2}} R_{2}^{2}-\frac{Q_{1}}{2} r_{1}^{2}-\frac{b Q_{2}}{2} r_{2}^{2}
\end{aligned}
$$

and $G=J_{2}(\underline{\sigma}-\underline{X})-R_{1}-R_{2}-k$ defines a Von Mises type yield surface with $\underline{X}=\sum_{i=1}^{2} \underline{X_{i}}$ and $J_{2}(\underline{\sigma}-\underline{X})=$ $\sqrt{3 / 2\left(\underline{\sigma^{\prime}}-\underline{X^{\prime}}\right):\left(\underline{\sigma^{\prime}-X^{\prime}}\right)}$ where $\underline{X^{\prime}}$ and $\underline{\sigma^{\prime}}$ the deviatoric parts of $\underline{X}$ and $\underline{\sigma}$ and where $K, n, k$ are temperature, tempering ratio and steel grade dependant parameters.

Ageing potential is proposed in the form:

\footnotetext{
${ }^{1}$ Notation: $x$, second order tensor; $\underline{C}$, fourth order Hooke's tensor.
}

$\Omega_{\mathrm{v}}=\frac{Z^{2}}{2 L} \cdot t^{m-1} \cdot m \cdot D^{m}$

From (8) plastic strain rate evolution is:

$\dot{\varepsilon}_{\mathrm{p}}=\frac{\partial \Omega_{\mathrm{p}}}{\partial \underline{\sigma}}=\frac{3}{2} \dot{p} \cdot \frac{\underline{\sigma^{\prime}}-\underline{X^{\prime}}}{J_{2}(\underline{\sigma}-\underline{X})}$

and

$\dot{p}=\Omega_{\mathrm{p}}^{\prime}(f)=\left\langle\frac{f}{K}\right\rangle^{n}=\left[\frac{2}{3} \dot{\varepsilon}_{\mathrm{p}}: \underline{\dot{\varepsilon}}_{\mathrm{p}}\right]^{\frac{1}{2}}$

is the cumulated plastic flow rate and flow rules of the internal variables are written as follows:

$\dot{\alpha}=-\frac{\partial \Omega_{\mathrm{p}}}{\partial \underline{X}}=\dot{\dot{\varepsilon}}_{\mathrm{p}}-c \cdot \underline{\alpha} \cdot \dot{p}$
$\dot{r}_{1}=-\frac{\partial \Omega_{\mathrm{p}}}{\partial R_{1}}=\dot{p}$ and $\dot{r}_{2}=-\frac{\partial \Omega_{\mathrm{p}}}{\partial R_{2}}=\dot{p}\left(1-b \cdot r_{2}\right)$

Ageing variable flow equation is derived from expression (9):

$\dot{\tau}_{\mathrm{v}}=-\frac{\partial \Omega_{\mathrm{v}}}{\partial Z}=-\frac{Z}{L} \cdot t^{m-1} \cdot m \cdot D^{m}$

Combining Eqs. (6) and (14), ageing parameter evolution expression can be rewritten:

$\dot{\tau}_{\mathrm{v}}=\left(1-\tau_{\mathrm{v}}\right) \cdot t^{m-1} \cdot m \cdot D^{m}$

This later equation corresponds to the tempering ratio rate obtained by derivation of the tempering kinetic law $\tau_{\mathrm{v}}=1-\exp \left(-(D \cdot t)^{m}\right)$ reported in Section 2.3 and Ref. [22]. For numerical simulation purposes with complex time-temperature routes, the following equation is preferred:

$\dot{\tau}_{\mathrm{v}}=\left(1-\tau_{\mathrm{v}}\right) \cdot t^{m-1} \cdot m \cdot D^{m}=\left(1-\tau_{\mathrm{v}}\right) \cdot m \cdot D \cdot\left[\ln \left(\frac{1}{1-\tau_{\mathrm{v}}}\right)\right]^{\frac{m-1}{m}}$

Under the assumption of decoupling the thermal dissipation and intrinsic dissipation, the second principle can be written:

$\Theta=\underline{\sigma}: \underline{\dot{\varepsilon}}_{\mathrm{p}}-R_{1} \cdot \dot{r}_{1}-R_{2} \cdot \dot{r}_{2}-\underline{X}: \underline{\dot{\alpha}}-Z \cdot \dot{\tau}_{\mathrm{v}}$

namely:

$$
\begin{aligned}
\Theta= & G \cdot \dot{p}+\frac{3}{2 a} \dot{p} \cdot \underline{X}: \underline{X}+\left(k+\frac{R_{2}^{2}}{Q_{2}}\right) \cdot \dot{p} \\
& +\frac{Z^{2}}{L} m \cdot D^{m} \cdot t^{m-1} \geqslant 0
\end{aligned}
$$

where the first three terms correspond, respectively, to viscous, kinematic and isotropic flow dissipations. The last one represents the ageing dissipation of the steel. Intrinsic dissipation is always positive and shows that the model is in agreement with the thermodynamic principles. 


\subsection{Identification methodology}

Model parameter identification is performed using the SiDoLo software [29]. Differential equations of the unidirectional model formulation are implemented in user subroutines with Fortran language. Minimising the difference between test results and model prediction, the model parameters are obtained after an iterative optimisation process.

Identification methodology of model parameters including ageing effect is done in three successive steps:

(i) Identification of ageing kinetic law parameters $\left(H_{0}\right.$, $H_{\propto}, D_{0}, Q$ and $m$ ) using hardness measurements for various times and temperatures. A detailed description can be found in Ref. [22] and results have been reported in Section 2.3.

(ii) Identification of the eleven elasto-visco-plastic cyclic model parameters from isothermal fatigue tests (test type one and two) conducted for different tempered states and for temperatures assuming that micro-structure is stable during the duration of the cyclic testing (i.e. between $15 \mathrm{~min}$ and $1 \mathrm{~h}$ ). Detailed identification procedure and methodology can be found in Refs. $[4,5,23]$.

An example that shows the quality of the identification process is shown in Fig. 4 for a type 2 test performed on a $475 \mathrm{HV}_{0.2}$ sample tested at $300{ }^{\circ} \mathrm{C}$. This result can only be obtained if plastic strain memory effects are integrated in the model: if strain amplitude is increased after a previous linear softening is achieved (for example from $\pm 0.6 \%$ to $\pm 0.7 \%$, respectively, to $\pm 0.8 \%$ and $\pm 0.9 \%$ ), a new rapid non-linear cyclic softening appears. In the opposite, if strain amplitude is decreased from $\pm 0.9 \%$ to $\pm 0.7 \%$, softening remains linear, and moreover lies in the continuity of the linear softening curve obtained for the previous $\pm 0.7 \%$ cycles (shown as a dashed line in Fig. 4).

(iii) Determination of relation between each cyclic model parameters and the tempering ratio calculated just before starting the cycling. Indeed, micro-structure may evolve during the heating up, and the $75 \mathrm{~s}$ temperature stabilisation before starting the cycling (see Ref. [25] for more details).

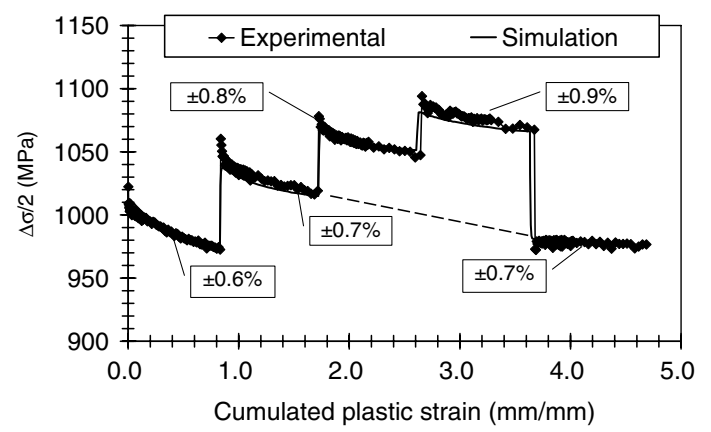

Fig. 4. Half-stress amplitude-cumulated plastic strain for a type two test on sample $475 \mathrm{HV}_{0.2}$ tested at $300{ }^{\circ} \mathrm{C}$ : experiment-simulation comparison.

\subsection{Model parameters results}

The evolution of all isothermal cyclic model parameters with the corresponding tempering ratio parameter calculated before cycling is presented in Fig. 5. Except for Young's modulus $E$ and $\mu$ (parameter related to strain memory), not shown in Fig. 5, all parameters significantly evolve with tempering ratio.

For a given temperature all parameters vary linearly with tempering ratio. Therefore, a general linear equation is proposed for all parameters, in the form:

$P=P\left(T, \tau_{\mathrm{v}}\right)=P_{0}(T)+P_{0}^{*}(T) \cdot\left(1-\tau_{\mathrm{v}}\right)$

where $T$ is in ${ }^{\circ} \mathrm{C}$.

A simplified equation can be used for kinematic hardening parameters $c_{i}$ and isotropic hardening variable $Q_{1}$, as no temperature dependence was observed:

$P=P_{0}+P_{0}^{*} \cdot\left(1-\tau_{\mathrm{v}}\right)$

If $\tau_{\mathrm{v}}=0$ (respectively $\tau_{\mathrm{v}}=1$ ), $P$ represents the material parameter for the quenched state of the steel (respectively for the annealed state of the steel).

Above-mentioned equations were then introduced in the identification software SiDoLo, as well as the tempering ratio evolution Eq. (16), and a new global identification process taking into account all experimental results was performed in two successive steps. This new identification integrates the possibility of micro-structure evolution during the fatigue cycling.

Step 1. $P_{0}$ and $P_{0}^{*}$ identification for kinematic and viscous parameters.

For a given temperature, all experimental stress-strain loops stored during test type one for the three strain rates $\left(10^{-2} \mathrm{~s}^{-1}, 10^{-3} \mathrm{~s}^{-1}, 10^{-4} \mathrm{~s}^{-1}\right)$ and for the four tempered states are simultaneously considered in the optimisation process, i.e. 12 experimental stress-strain loops. An example is shown Fig. 6 for tests performed at $500{ }^{\circ} \mathrm{C}$.

Step 2. $P_{0}$ and $P_{0}^{*}$ identification for isotropic parameters and true elastic limit.

For a given temperature, all cyclic softening curves $\Delta \sigma / 2-p$ gathered for all tempering states are simultaneously used. Fig. 7a and $\mathrm{b}$ are reporting two experimental-simulated comparisons at room temperature and $300^{\circ} \mathrm{C}$.

Finally, all model parameters are summarised in Table 3.

\section{Cyclic fatigue-ageing model validation}

Model predictive capabilities have been validated in two different and complementary situations.

(i) First validation condition concerns samples subjected to testing temperatures higher than the tempering ones. In such conditions, micro-structure evolution occurs during the cyclic testing. Fig. 8 shows the good 

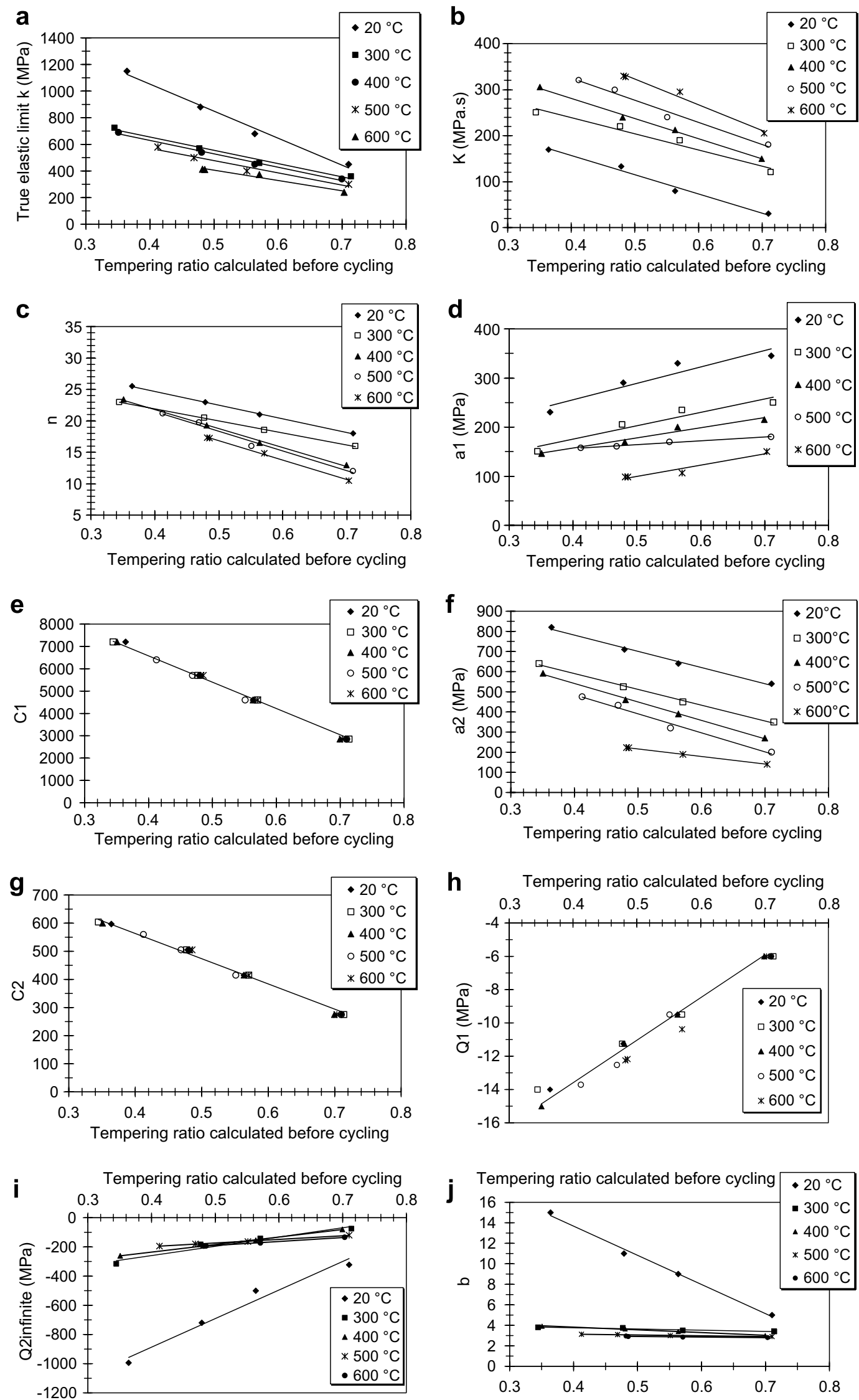

Fig. 5. Cyclic model parameters evolution according to the tempering ratio calculated at the beginning of cycling: (a) true elasticity limit, (b) K, (c) $n$ : strain rate exponent, (d,e,f,g) $a 1, c 1, a 2, c 2$ : kinematic hardening parameters, $(\mathrm{h}, \mathrm{i}, \mathrm{j}) Q 1, Q 2 \propto, b$ : isotropic hardening parameters. 

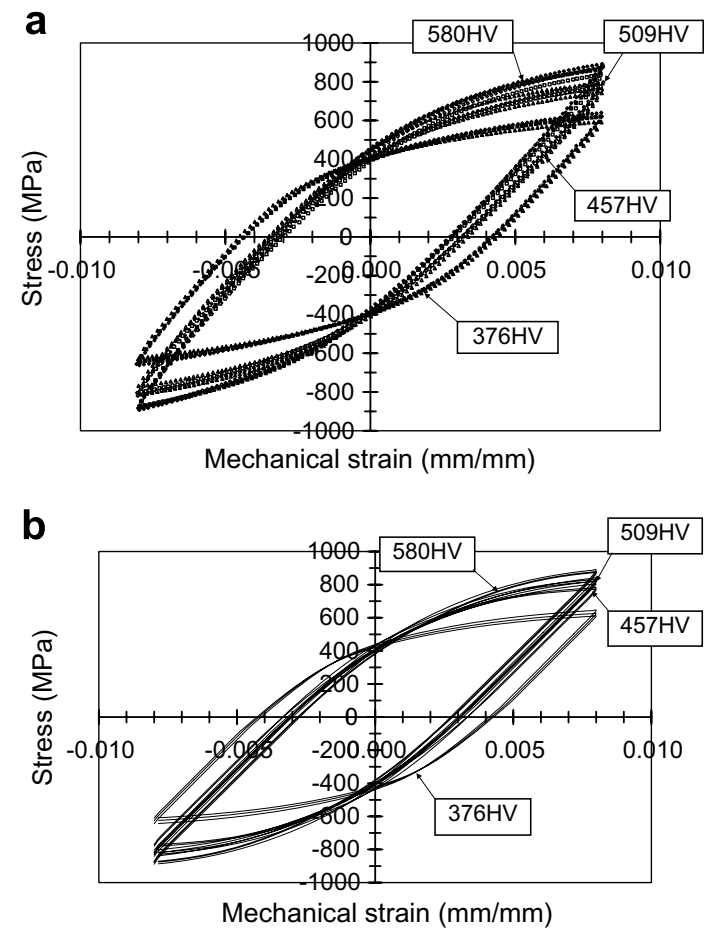

Fig. 6. Stress-strain loops at $500{ }^{\circ} \mathrm{C}$ for three strain rates $\left(10^{-2} \mathrm{~s}^{-1}\right.$, $\left.10^{-3} \mathrm{~s}^{-1}, 10^{-4} \mathrm{~s}^{-1}\right)$ and for the four investigated initial hardness $\left(\Delta \varepsilon_{\mathrm{t}}= \pm 0.8 \%\right)$ : (a) experimental, (b) simulation.

agreement between experiment and simulation for successive stress-strain loops during fatigue testing of a $580 \mathrm{HV}_{0.2}$ sample (tempered at $350{ }^{\circ} \mathrm{C}$ ) tested at $600{ }^{\circ} \mathrm{C}$. During this test, tempering ratio parameter varies as shown in Fig. 9, indicating an important evolution of micro-structure and hardness (approximately $30 \mathrm{HV}_{0.2}$ ).
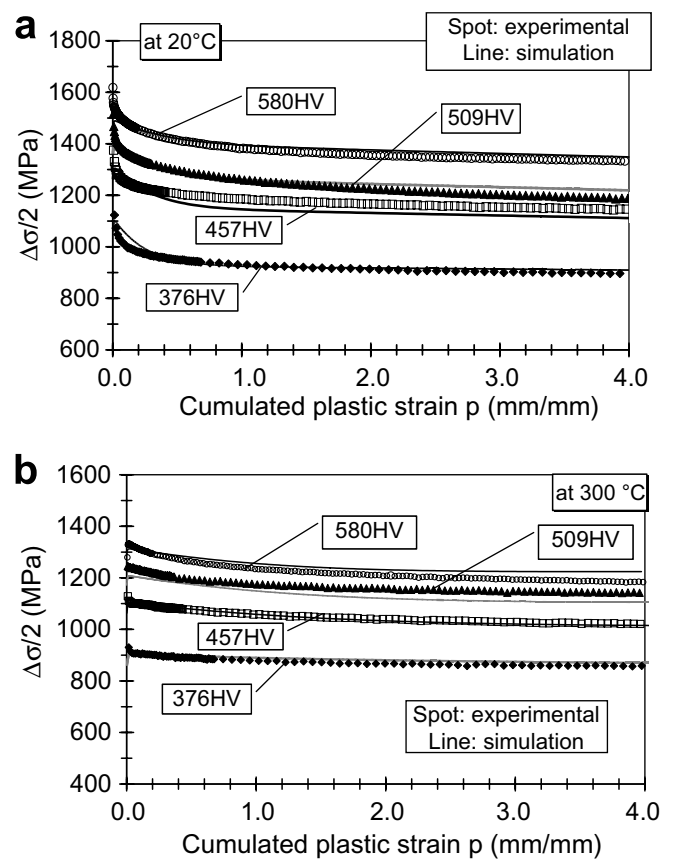

Fig. 7. Half-stress amplitude versus cumulated plastic strain, experimental-simulation comparison: (a) room temperature, (b) $300{ }^{\circ} \mathrm{C}$.

Fig. 10 shows that the model is also able to predict the evolution of the half-stress amplitude for all the samples tested at $600{ }^{\circ} \mathrm{C}$, whatever the initial hardness. Indeed, three samples $\left(580 \mathrm{HV}_{0.2}, 509 \mathrm{HV}_{0.2}\right.$ and $\left.475 \mathrm{HV}_{0.2}\right)$ are tested at temperatures higher than the tempering temperature. On the opposite, the $376 \mathrm{HV}_{0.2}$ sample is tested at the same temperature than the tempering one. For the simulation, the whole heating up and waiting period before cyclic testing

Table 3

Fatigue-ageing model parameters

\begin{tabular}{|c|c|c|c|c|c|c|c|}
\hline Parameter & $T$ & $P_{0}$ & $P_{0}^{*}$ & Parameter & $T$ & $P_{0}$ & $P_{0}^{*}$ \\
\hline \multirow[t]{5}{*}{$K(\mathrm{MPa} \mathrm{s})$} & $20^{\circ} \mathrm{C}$ & -87.25 & 498.54 & $k(\mathrm{MPa})$ & $20^{\circ} \mathrm{C}$ & 352.09 & -363.53 \\
\hline & $300^{\circ} \mathrm{C}$ & -38.8 & 1178.61 & & $300^{\circ} \mathrm{C}$ & 406.09 & -805.35 \\
\hline & $400^{\circ} \mathrm{C}$ & -87.95 & 704.77 & & $400^{\circ} \mathrm{C}$ & 246.36 & -22.33 \\
\hline & $500^{\circ} \mathrm{C}$ & -95.27 & 1422.56 & & $500^{\circ} \mathrm{C}$ & 391.29 & -977.94 \\
\hline & $600^{\circ} \mathrm{C}$ & 195.35 & 1069.6 & & $600^{\circ} \mathrm{C}$ & 203.23 & -985.54 \\
\hline \multirow[t]{5}{*}{$n$} & $20^{\circ} \mathrm{C}$ & 1.01 & 64.09 & $b$ & $20^{\circ} \mathrm{C}$ & -0.96 & 26.09 \\
\hline & $300^{\circ} \mathrm{C}$ & 16.27 & 59.1 & & $300^{\circ} \mathrm{C}$ & 3.13 & 1.15 \\
\hline & $400^{\circ} \mathrm{C}$ & 1.1 & 23.49 & & $400^{\circ} \mathrm{C}$ & 2.79 & 1.73 \\
\hline & $500^{\circ} \mathrm{C}$ & 2.69 & 43.06 & & $500^{\circ} \mathrm{C}$ & 2.76 & 0.63 \\
\hline & $600^{\circ} \mathrm{C}$ & 6.06 & 13.44 & & $600^{\circ} \mathrm{C}$ & 4.87 & -0.026 \\
\hline \multirow[t]{5}{*}{$a_{1}(\mathrm{MPa})$} & $20^{\circ} \mathrm{C}$ & 117.88 & 321.63 & $Q_{2 \infty}(\mathrm{MPa})$ & $20^{\circ} \mathrm{C}$ & 150.3 & -1827.9 \\
\hline & $300^{\circ} \mathrm{C}$ & 221.41 & -65.2 & & $300^{\circ} \mathrm{C}$ & 138.7 & -822.72 \\
\hline & $400^{\circ} \mathrm{C}$ & 231.84 & -98.49 & & $400^{\circ} \mathrm{C}$ & -3.96 & -395.91 \\
\hline & $500^{\circ} \mathrm{C}$ & 100.35 & 57.18 & & $500^{\circ} \mathrm{C}$ & -58.87 & -273.76 \\
\hline & $600^{\circ} \mathrm{C}$ & 100.0 & 49.09 & & $600^{\circ} \mathrm{C}$ & 17.8 & 139.27 \\
\hline \multirow[t]{5}{*}{$a_{2}(\mathrm{MPa})$} & $20^{\circ} \mathrm{C}$ & 180.99 & 920.0 & $c_{1}$ & & 250 & 11515 \\
\hline & $300^{\circ} \mathrm{C}$ & 29.26 & 920.0 & $c_{2}$ & & 81.17 & 877.44 \\
\hline & $400^{\circ} \mathrm{C}$ & 132.22 & 646.04 & $Q_{1}(\mathrm{MPa})$ & & -1.35 & -21.04 \\
\hline & $500{ }^{\circ} \mathrm{C}$ & 115.19 & 371.99 & & & & \\
\hline & $600^{\circ} \mathrm{C}$ & 16.83 & 381.11 & & & & \\
\hline
\end{tabular}

Young's modulus $E=214324-103 \mathrm{~T}(\mathrm{MPa})$.

Poisson ratio $v=0.3, \mu=420$. 

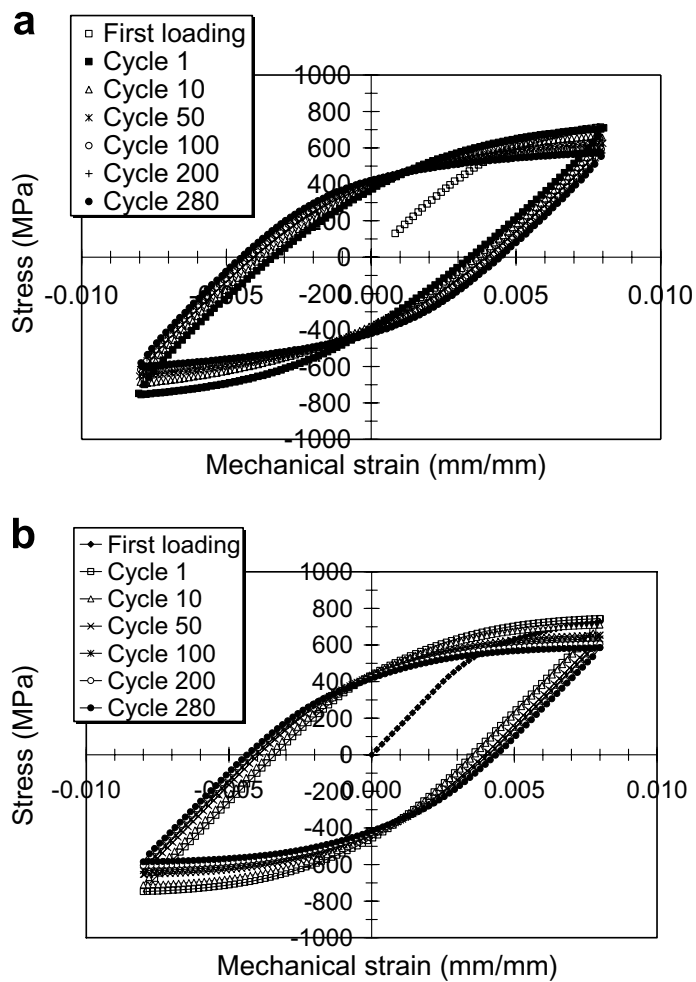

Fig. 8. Successive stress-strain loops for a $580 \mathrm{HV}_{0.2}$ sample tested at $600{ }^{\circ} \mathrm{C}\left(\Delta \varepsilon_{\mathrm{t}}= \pm 0.8 \%\right)$ : (a) experimental, (b) simulation.

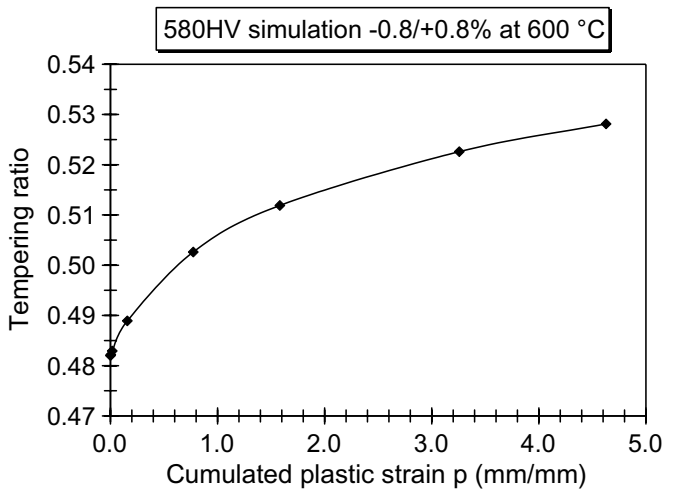

Fig. 9. Calculated tempering ratio evolution during isothermal fatigue of the $580 \mathrm{HV}_{0.2}$ sample tested at $600{ }^{\circ} \mathrm{C}\left(\Delta \varepsilon_{\mathrm{t}}= \pm 0.8 \%\right)$.

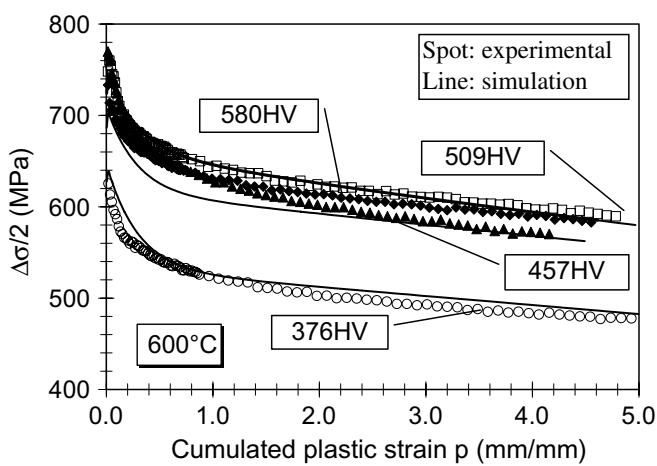

Fig. 10. Half-stress amplitude evolution at $600{ }^{\circ} \mathrm{C}$ : comparison between experiment and simulation. is taken into account. As a result the tempering ratio of the first three samples are close to each other before cycling (respectively $0.4820,0.4855,0.5708$ ), especially the two first, and consequently half-stress amplitude evolutions are close to each other. Calculated tempering ratio before cycling of the $376 \mathrm{HV}_{0.2}$ sample $(0.7032)$ is far above and the cyclic curve is clearly separated. Simulation and experiment are in very good agreement giving a first validation of the fatigue-ageing behaviour model in such conditions.

(ii) Second validation is performed using samples tempered at $500{ }^{\circ} \mathrm{C}$ for $2 \mathrm{~h}$ resulting in initial measured hardness of $495 \mathrm{HV}_{0.2}$. For this sample, the tempering ratio calculated with the kinetic model gives 0.4965 , whereas the measured one is 0.4964 . Fatigue-ageing model was used to predict the behaviour during a fatigue test performed at $500{ }^{\circ} \mathrm{C}$ under a total strain amplitude of $\pm 0.8 \%$ and a constant strain rate of $10^{-2} \mathrm{~s}^{-1}$.

Fig. 11 compares successive stress-plastic strain loops. Plastic strain amplitudes for all the cycles, as well as their rapid increase during the 100 first cycles are well predicted. During this test, only a low evolution of the tempering ratio is predicted (see Fig. 12). The predicted half-stress amplitude evolution during the cycling is plotted Fig. 13 and compared to the experimental one. If the general evolution is well predicted, the slight discrepancy observed

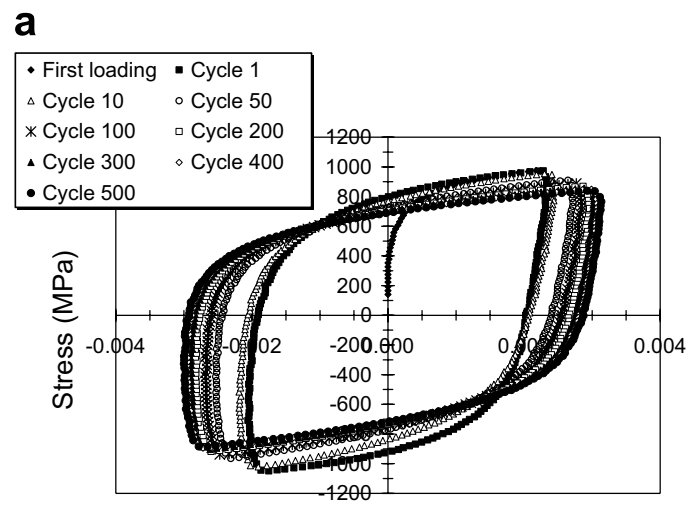

b

Plastic strain $(\mathrm{mm} / \mathrm{mm})$

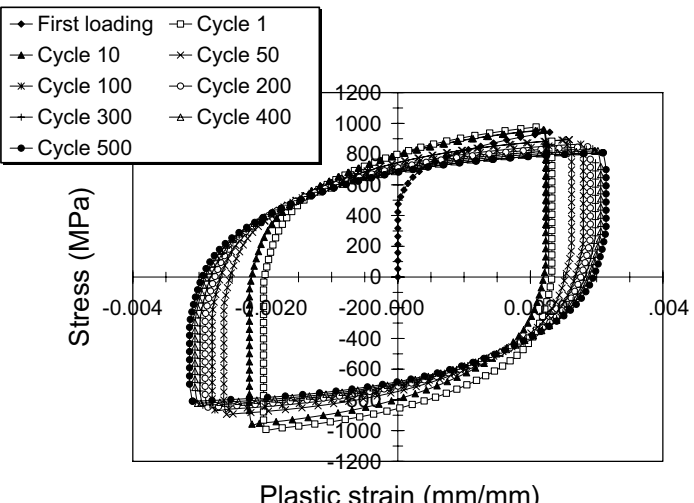

Fig. 11. Stress-plastic strain loops for the $495 \mathrm{HV}_{0.2}$ sample tested at $500{ }^{\circ} \mathrm{C}\left(\Delta \varepsilon_{\mathrm{t}}= \pm 0.8 \%\right)$ : (a) experimental, (b) simulation. 


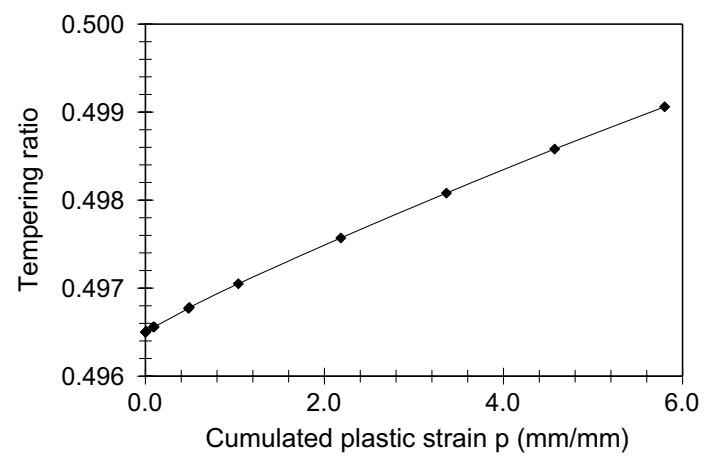

Fig. 12. Calculated tempering ratio evolution during isothermal fatigue of the $495 \mathrm{HV}_{0.2}$ sample tested at $500{ }^{\circ} \mathrm{C}\left(\Delta \varepsilon_{\mathrm{t}}= \pm 0.8 \%\right)$.

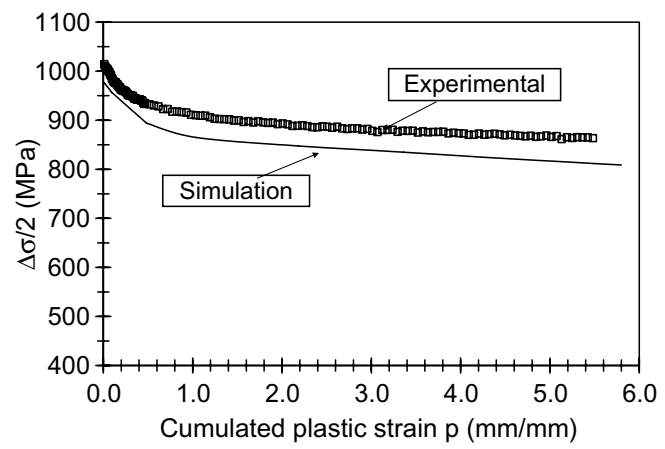

Fig. 13. Half-stress amplitude evolution for the $495 \mathrm{HV}_{0.2}$ sample tested at $500{ }^{\circ} \mathrm{C}\left(\Delta \varepsilon_{\mathrm{t}}= \pm 0.8 \%\right)$ : comparison between experiment and simulation.

$(5 \%)$ is attributed to the typical variation of the Young's modulus and true elastic limit from one sample to another taken in a same batch. Nevertheless this result obtained on a sample with a hardness not included in the identification process shows the reliable predictive capability of the fatigue-ageing model. Above all, whatever the tempering and the testing temperatures may be inside the investigated range, the proposed model is able to correctly simulate the fatigue behaviour of a quenched and tempered steel with a single set of identified parameters.

\section{Conclusion}

An anisothermal elasto-visco-plastic constitutive model taking into account the micro-structure evolution induced by time-temperature ageing was formulated in the frame of the thermodynamics of irreversible processes. Tempering ratio $\left(\tau_{\mathrm{v}}\right)$ and tempering kinetic law in the form of Johnson-Mehl-Avrami relation was introduced as a model internal variable to predict the micro-structure evolution. Concerning the model parameter identification, a special test program was conducted using samples with four initial decreasing hardness levels. An optimised testing procedure and corresponding identification process has required only two samples per temperature in order to determine the eleven model parameters at each temperature. The quality of the identification process has been checked for all the tests.

Evolution of all model parameters with tempering ratio and temperature was found to follow a general linear equation. After the introduction of these relations and tempering ratio evolution with time and temperature in the identification procedure, the identification process was done again for each temperature, in one shot, taking into account all experimental curves registered for all hardness levels.

Validation of fatigue-ageing model was performed by comparing stress-strain loops and half-stress amplitude evolution predictions with experimental results on samples presenting a micro-structure evolution during cyclic testing, and on samples with an initial hardness (i.e., tempering ratio) different from those used in the parameter identification process. In both cases results are in good agreement with experimental results and, moreover, the model gives interesting indications on the micro-structure evolution process in plotting the tempering ratio evolution along the material sample history.

As a result, such kind of fatigue-ageing model has a direct industrial interest for tempered martensitic tools steels. First it allows the knowledge of the fatigue model parameters whatever the initial tempering conditions applied on a die, without a new testing campaign. Second it permits to take into account the micro-structural evolution of local zones of a die (for example close to the surface) in an design simulation procedure in relation with life time prediction.

\section{Acknowledgements}

The authors gratefully acknowledge the Thyssen France Company for supplying the steel investigated and SRF for ROCS, SEM for financial support.

\section{References}

[1] Miller AK. The MATMOD equation, unified constitutive equations for creep and plasticity. London: Elsevier Applied Science; 1987. p. $139-219$.

[2] Chaboche JL. Constitutive equations for cyclic plasticity and cyclic viscoplasticity. Int J Plast 1989;5:247-302.

[3] Zhang Z, Delagnes D, Bernhart G. Stress-strain behaviour of tool steels under thermo-mechanical loadings: experiments and modelling. In: Jeglitsch F, Ebner R, Leitner H, editors. Proceedings of the 5th international tooling conference. Austria: University of Leoben; 1999. p. 205-13.

[4] Velay V, Bernhart G, Zhang ZP, Penazzi L. Cyclic behaviour modeling of martensitic hot work tool steels. In: Biallas G, Maier HJ, editors. Proceedings of CAMP2002, high-temperature fatigue. Paderborn, Germany; 3-4 April 2002. p. 64-75.

[5] Zhang Z, Delagnes D, Bernhart G. Anisothermal cyclic plasticity modelling of martensitic steels. Int J Fatigue 2002;24(6):635-48.

[6] Velay V, Bernhart G, Penazzi L. Cyclic behavior modeling of a tempered martensitic hot work tool steel. Int J Plast 2005;22:459-96.

[7] Komanduri R, Hou ZB. Thermal modeling of the metal cutting process - part II: temperature rise distribution due to frictional heat source at the tool-chip interface. Int J Mech Sci 2001;43(1):57-88. 
[8] Gibbons CL, Dunn JE. Investigations of reduced service life of hot work (Cr-Mo) die steel pieces. Ind Heat 1980;47:6-9.

[9] Hamata N. Modélisation du couplage entre l'élasto-viscoplasticité anisotherme et la transformation de phase d'une fonte G.S. ferritique. PhD thesis Université Paris 6, 1992 [in French].

[10] Denis S, Gautier E, Simon A, et al. Stress-phase-transformation interactions - basic principles modelling and calculation of internal stresses. Mater Sci Technol 1984;1:805-14.

[11] Denis S, Sjostrom S, Simon A. Coupled temperature, stress, phase transformation calculation, model numerical illustration of the internal stresses evolution during cooling of an eutectoid carbon steel cylinder. Metall Trans A 1987;18A:1203-11.

[12] Inoue T, Nagaki S, Kishino T, Monkawa M. Description of transformation kinetics, heat conduction and elastic-plastic stress in the course of quenching and tempering of some steels. Ing Archiv 1981;50:315-27.

[13] Rammersorfer FG, Fischer DF. On thermo-elastic-plastic analysis of heat treatment processes including creep and phase changes. Comput Struct 1981;13:771-9.

[14] Leblond JB, Mottet G, Devaux JC. A theoretical and numerical approach to the plastic behavior of steels during phase transformations-I. Derivation of general relations. J Mech Phys Solids 1986;34:395-409.

[15] Cailletaud G. Modélisation mécanique d'instabilités microstructurales en viscoplasticité cyclique à température variable. $\mathrm{PhD}$ thesis Université Paris 6, 1979 [in French].

[16] Cailletaud G, Depoid C, Massinon D. Elastoviscoplasticity with ageing in aluminium alloys. In: Mangin, editor. Continuum thermomechanics: The art \& science of modeling material behaviour. Kluwes; 2000. p. 75-86.

[17] Nicouleau-Bourles E. Etude expérimentale et numérique du vieillissement d'un alliage d'aluminium-application aux culasses automobiles. PhD thesis ENSMP, 1999 [in French]

[18] Marquis D. Phénoménologie et thermodynamique: couplages entre thermoélasticité, plasticité, vieillissement et endommagement. $\mathrm{PhD}$ thesis Université Paris 6, 1989 [in French].
[19] Chaboche JL, El Mayas N, Paulmier P. Modélisation thermodynamique des phénomènes de viscoplasticité, restauration et vieillissement. CR Acad Sci Paris 1995;320(II):9-16.

[20] Smith TJ, Sehitoglu H, Qing XL, et al. The influence of SDAS on TMF response of AL 319 alloys. In: Rie K-T, Portella PD, editors. Low cycle fatigue and elasto-plastic behaviour of materials. Netherland, Amsterdam: Elsevier; 1998. p. 167-72.

[21] Devy F. Description, modélisation et simulation de la trempe des superalliages. PhD thesis, Université Paris 6, 1991 [in French].

[22] Zhang Z, Delagnes D, Bernhart G. Microstructure evolution of hotwork tool steels during tempering and definition of a kinetic law based on hardness measurements. Mater Sci Eng A 2004;380(1-2): $222-30$.

[23] Zhang Z. Anisothermal cyclic behaviour modelling with taking account of tempering effect of a martensitic tool steel $55 \mathrm{NiCrMoV7}$. $\mathrm{PhD}$ thesis, ENSMP, 2002 [in French].

[24] Zhang Z, Delagnes D, Bernhart G. Tempering effect on cyclic behaviour of a martensitic tool steel. In: Bergström J, Fredriksson G, Johansson M, Kotik O, Thuvander F, editors. Proceedings of the 6th international tooling conference: the use of tool steels: experience and research, September 2002. Sweden: Karlstad University; 2002. p. $573-89$.

[25] Zhang Z, Delagnes D, Bernhart G. Ageing effect on cyclic plasticity of a tempered martensitic steel. Int J Fatigue 2007;29(2):336-46.

[26] Bernhart G, Moulinier G, Brucelle O, Delagnes D. High temperature low cycle fatigue behaviour of a martensitic forging tool steel. Int $\mathbf{J}$ Fatigue 1999;21(2):179-86.

[27] Mebarki N, Delagnes D, Lamesle P, et al. Relationship between microstructure and mechanical properties of a $5 \% \mathrm{Cr}$ tempered martensitic tool steel. Mater Sci Eng A 2004;387389(1-2):171-5.

[28] Chaboche JL. Sur les lois de comportement des matériaux sous sollicitations monotones ou cycliques. La recherche aérospatiale 1983;5:363-75.

[29] Pilvin P. SiDoLo, Notice d'utilisation; 1985. 